\title{
BIOTECNOLOGIAS E A (R)EVOLUÇÃO NOS MODOS DE SUBJETIVAÇÃO
}

\author{
Neuza Maria de Fátima Guareschi* \\ Marcos Adegas de Azambuja\# \\ Lutiane de Lara"
}

\begin{abstract}
RESUMO. Este artigo tem como objetivo discutir a temática da saúde no contexto da Reforma Sanitária e as demandas que esse processo coloca para as práticas psicológicas. Entendemos a partir da leitura de Michel Foucault que a saúde (saúde pública) é uma forma de investimento na vida, ou seja, a saúde é tomada pela biopolítica como estratégia de governo da população. Em um primeiro momento, fundamentamos a discussão da biopolítica e da saúde. Em um segundo momento, analisamos como a Psicologia entra no campo da saúde, entendendo que este saber se construiu na perspectiva do desenvolvimento como inerente à natureza humana. Em um terceiro momento, situamos as repercussões das produções biotecnológicas das sociedades contemporâneas a partir da noção de uma evolução artificial, presente hoje no "desenvolvimento" humano. Finalmente, apontamos como as práticas psicológicas em saúde devem também levar em conta as produções da biotecnologia na promoção da qualidade de vida.
\end{abstract}

Palavras-chave: Saúde; práticas da Psicologia; biotecnologia.

\section{BIOTECHNOLOGIES AND THE (R)EVOLUTION IN THE WAYS OF SUBJECTIFICATION}

\begin{abstract}
This paper aims at discussing about health in the context of the Health Reform and the demands that this process implies in terms of psychological practices. We understand health as a bio-political strategy, according to the Foucauldian theoretical perspective, i.e. as in investment in population life. Firstly, we discuss both bio-policy and health. Secondly, we analyze the way Psychology has entered the health field, understanding that this knowledge has been built on the perspective of development as inherent to human nature. Thirdly, we identify repercussions of biotechnological productions of contemporary societies from the notion of an artificial evolution, currently present in human 'development'. Finally, we point out that psychological practices in health should also take into consideration the biotechnology productions in promoting quality of life.
\end{abstract}

Key words: Health; psychological practices; biotechnological.

\section{BIOTECNOLOGÍA (R)EVOLUCIÓN EN LOS MODOS DE LA SUBJETIVIDAD}

RESUMEN. Este artículo tiene como objetivo discutir el tema de la salud en el contexto de la reforma de la salud y las demandas que plantea este proceso a las prácticas psicológicas. Nosotros entendemos la salud como una estrategia biopolítica, según lo propuesto en la perspectiva teórica de Foucault, es decir, un investimiento en la vida de las personas. En un primer momento, la discusión se fundamenta en la biopolítica y la salud. En una segunda etapa, se analizó como la psicología entra en el campo de la salud, entendiendo que este conocimiento se construye desde la perspectiva del desarrollo como algo inherente en la naturaleza humana, así que, en una tercera vez, situamos el impacto de las producciones biotecnológicas de las sociedades contemporáneas con la noción de una evolución artificial, hoy presente en el "desarrollo" humano. Por último, se

Doutora em Educação pela University of Wisconsin-Madison (1998); professora adjunta da Universidade Federal do Rio Grande do Sul, Brasil.

\# Doutor em Psicologia pela Pontifícia Universidade Católica do Rio Grande do Sul (2012); professor adjunto do Centro Universitário Franciscano e convidado da Universidade Comunitária da Região de Chapecó, Brasil.

II Mestre em Psicologia Social e da Personalidade pela Pontifícia Universidade Católica do Rio Grande do Sul (2009); doutoranda do Programa de Pós-Graduação em Psicologia Social e Institucional da UFRGS, bolsista CAPES, Brasil. 
señalan las prácticas psicológicas en la salud que también deben tener en cuenta la producción de la biotecnología en un incremento de la calidad de vida

Palabras-clave: Salud; prácticas psicológicas; biotecnología.

O presente artigo trata da temática das relações de saber e poder nos processos de subjetivação produzidos pelas práticas psicológicas na saúde. Discutiremos o contexto contemporâneo caracterizado pela relação entre o poder e a vida. Tal relação vem organizando os modos de existência para que se potencialize e promova o melhoramento da vida humana - uma biopolítica: a vida, ou o modo de viver, é o objeto de investimento de um poder que penetrou na existência do corpo, dos órgãos, da circulação dos genes, produzindo modos de subjetivação. Para analisarmos esses contextos contemporâneos - de investimento na vida -, seguiremos os passos de Michel Foucault (2008) indicados em sua primeira aula, no início de seu curso "Nascimento da biopolítica", em 1979. Diz ele que seu método apesar de sabermos das controvérsias quando utilizamos esta palavra com este pensador - é o inverso de qualquer historicismo: (...) "em lugar de partir desses universais como grade de inteligibilidade obrigatória para uma série de práticas concretas, gostaria de começar por estas últimas e, de algum modo, passar os universais pela grade dessas práticas" (p. 18). Supondo a inexistência de verdades absolutas, ele pergunta o que se pode fazer com a história. Enfim, a partir daquilo que é tomado como uma evidência, passa-se a olhar as verdades absolutas como um problema, e dessa maneira, exercemos um processo de desnaturalização dos universais cristalizados (Silva, 2004).

Não está posto aqui que estejamos descartando a história, pois entendemos que a ontologia do ser humano é histórica e que essa história acontece nos diferentes modos de subjetivação; portanto, torna-se necessário compreender a experiência subjetiva como produzida pelas práticas e técnicas que se desenrolam na história, e não o contrário, com a experiência produzindo tais dispositivos (Rose, 2001a). É importante ainda compreender a experiência subjetiva como constituída pela linguagem, e por outro lado, a linguagem não apenas como instrumento que liga o pensado à coisa falada (lógica representacionista), mas como constitutiva do pensamento, e, em decorrência, do sentido que damos às coisas, à nossa experiência, ao mundo. Nesse caminho, Foucault volta-se para a análise das relações da linguagem consigo mesma e das relações entre a linguagem e o mundo. Essa compreensão de linguagem faz com que o que se diz sobre as coisas (podendo ser derivado de conhecimento científico, cultura, senso comum, etc.) seja produto de discursos cuja logicidade é construída e cuja fundamentação tem de ser sempre buscada fora de si (Veiga-Neto, 2005). Foucault define discurso como "o conjunto de enunciados que derivam de um mesmo sistema de formação; sendo possível falar de discurso desenvolvimentista, discurso da saúde pública, discurso da evolução natural, discurso psicológico" (Foucault, 2004). Os discursos não são o resultado de combinações de palavras, mas eles formam os objetos de que falam; portanto, a proposta é fazer a história dos acontecimentos que tornaram possível o presente, uma história sempre atravessada pelas relações entre as estruturas da racionalidade que articulam o discurso verdadeiro e os mecanismos de assujeitamento que as liga entre si. As práticas de Psicologia em saúde, neste artigo, são tomadas como uma forma de pensarmos sobre essa história, que se unificou e se tornou verdadeira, a respeito das práticas psicológicas na saúde.

Este artigo tem como objetivo discutir a temática da saúde no contexto da Reforma Sanitária e consequentemente as demandas que esse processo coloca para as práticas psicológicas. Entendemos a partir da leitura de Michel Foucault que a saúde (saúde pública) é uma forma de investimento na vida, ou seja, a saúde é tomada pela biopolítica como estratégia de governo da população. Em um primeiro momento, fundamentamos a discussão da biopolítica e a saúde. Em um segundo momento, analisamos como a Psicologia entra no campo da saúde, entendendo que este saber se construiu na perspectiva do desenvolvimento como inerente à natureza humana. Em um terceiro momento, situamos as repercussões das produções biotecnológicas das sociedades contemporâneas a partir da noção da evolução artificial, presente hoje no "desenvolvimento" humano. Finalmente, apontamos como as práticas psicológicas em saúde devem também levar em conta as produções da biotecnologia na promoção da qualidade de vida.

\section{BIOPODER: INVESTIMENTO NA VIDA}

As práticas psicológicas em saúde estão amarradas a um processo histórico marcado pelo 
investimento massivo na vida, característico da Modernidade. É nesta construção que o humano, como espécie, passou a ser alvo de uma política, de uma "estatização do biológico". A intervenção bipolítica na população procuraria controlar as contingências dos fenômenos inerentes à vida, de forma a controlar a probabilidade desses fenômenos para compensar seus efeitos. O poder exercido pela biopolítica seria o poder para fazer viver no "como" da vida para otimizá-la ao máximo (Foucault, 2005).

A biopolítica, ao agregar as práticas disciplinares aos mecanismos de regulamentação, coloca-se entre o disciplinar e o regulamentador, de modo a controlar a ordem disciplinar do corpo e os acontecimentos aleatórios de uma multiplicidade biológica. Os vetores - disciplina e biopolítica - se articularam no contexto do Estado moderno como dois conjuntos de técnicas orientadas para a dominação, e é isso que Foucault (2005) denomina biopoder. A saúde entra como parte das estratégias do biopoder para fazer a gestão da vida, a fim de maximizá-la e potencializá-la cada vez mais através da otimização da qualidade biológica. $\mathrm{O}$ governo da população assume uma importância central para os saberes que buscam a regulação dos comportamentos nas instituições sociais (Foucault, 2003, p. 133).

A biopolítica é uma estratégia de poder que realiza o manejo da população e, ao mesmo tempo, disciplina os corpos. O evolucionismo darwiniano, a partir do século XIX, em seu conjunto de noções "hierarquia das espécies sobre a árvore comum da evolução, luta pela vida entre as espécies, seleção que elimina os menos adaptados" (Foucault, 2005, p.307) -, tornou-se uma maneira científica de pensar a colonização, as guerras, a criminalidade, a loucura, a sociedade de classes, etc. "Em outras palavras, cada vez que houve enfrentamento, condenação à morte, luta, risco de morte, foi na forma do evolucionismo que se foi forçado, literalmente, a pensá-los" (Foucault, 2005, p.307).

O biopoder utilizou a perspectiva da evolução gradativa das espécies e, em especial, da espécie humana para legitimar os critérios das vidas que devem ser investidas e quais devem ser desinvestidas. $\mathrm{O}$ poder de morte, princípio contrário ao objetivo de potencializar a vida, sustenta-se no biopoder através da estatização do mecanismo do racismo. A primeira função do racismo de Estado será a de fragmentar, estabelecendo cortes no contínuo biológico da espécie humana. $\mathrm{O}$ aparecimento das raças, de suas distinções e hierarquias do sistema de qualificação fragmenta o campo biológico e, dessa maneira, torna um grupo populacional inferior em relação a outro, como no caso histórico da raça ariana em relação aos judeus. A segunda função desse mecanismo de racismo será a de estabelecer uma relação positiva na seguinte equação: "quanto mais você matar, mais fará viver". O racismo de Estado vai legitimar a relação presente há muito nas guerras: "se você quer viver, é preciso que outro morra" (Foucault, 2005).

Tirar a vida no biopoder será admissível quando acontecer em prol de um benefício biológico que resulte no fortalecimento das raças "superiores" em detrimento das "inferiores". Isso explica como, em uma sociedade de biopoder, é possível aumentar os riscos de morte, expor à morte, à morte política, à expulsão e à rejeição.

\section{SAÚDE E QUALIDADE DE VIDA}

As amarrações do biopoder repercutiram na construção das práticas de saúde contemporâneas do Brasil. Essas mudanças evidenciam como a produção biopolítica - e, claro, as relações de saber-poder envolvem-se com todas as esferas da vida da população. $\mathrm{O}$ envolvimento do biopoder intensificouse com as mudanças geradas na compreensão e no fazer em saúde a partir da segunda metade do século XX. O conceito de saúde dominante até a década de 1960 definia a saúde como a ausência de doença. O corpo humano era percebido como uma constante morfológica e funcional, o que gerava a construção de verdades universais sobre a saúde dos sujeitos. Esse saber dicotômico sobre a saúde é decorrência da centralidade das ciências positivas no campo da saúde, que a compreendiam como uma realidade externa e anterior às alterações concretas do corpo dos doentes. O corpo seria desconectado de todo o conjunto de relações que envolvem o viver (Czeresnia, 2003). As práticas de saúde desse modelo produziram um investimento na saúde da população limitado aos fatores biológicos e sustentado por uma concepção de saúde que volta seu olhar para o sintoma a fim de retirá-lo, extraí-lo e restituir a "normalidade". Tal perspectiva filia-se a termos como "eliminação", "higienismo", "contaminação", "isolamento". As muitas críticas que surgem em relação a esse conceito e, por consequência, a essas práticas em saúde, apontam para a observação de um sujeito descontextualizado e determinado pelo biológico.

A partir da segunda metade do século XX a centralidade desse modelo positivo foi posta em questão e outros fatores além do biológico passaram a ser considerados na formulação do conceito de saúde. A noção de saúde não se preocuparia mais, pura e simplesmente, com a doença - sua prevenção, 
controle, eliminação ou manutenção -, mas também com a promoção de saúde. Destarte, a promoção da saúde é fundamental para superar o entendimento de que saúde é ausência de doença. Essa noção sustentou a defesa de outro modelo de saúde que investe na prevenção, promoção, proteção e recuperação de saúde ao considerar que não são apenas os fatores biológicos que são determinantes para a saúde. A Lei 8.080/90, ao dispor sobre as condições para a promoção, proteção e recuperação da saúde, explicita que fatores como alimentação, moradia, saneamento básico, meio ambiente, trabalho, renda, educação, transporte, lazer e acesso aos bens e serviços essenciais passam a ser considerados determinantes e condicionantes para a saúde.

A concepção de saúde adotada na formulação do Sistema Único de Saúde para o Brasil, ao questionar o primado biologista, aproximou o conceito de saúde às condições de vida. Essa aproximação se dá pelo significado que a saúde adquiriu no texto da VIII Conferência Nacional de Saúde: "Direito à saúde significa a garantia, pelo Estado, de condições dignas de vida" (1986, s/p). O conceito de saúde passa ao se aproximar das condições de vida e a ter equivalência com a noção de vida. A saúde dirá respeito ao acesso e aos hábitos alimentares; dirá respeito às condições de moradia, se são consideradas dignas ou não; dirá respeito às condições do meio ambiente - se a pessoa vive em local poluído, se há reciclagem do lixo, se há reflorestamento; dirá respeito às condições de trabalho, se há oferta de trabalho e quais são as condições oferecidas; dirá respeito à educação - se a pessoa é alfabetizada, qual é a distância entre a escola e a casa do sujeito, sua escolaridade, etc.

Saúde e vida tornam-se equivalentes que remetem ao modo como as pessoas experienciam o mundo e como se relacionam com ele. Essa equivalência leva os sujeitos a produzirem-se como sujeitos de direitos, como cidadãos, através da garantia de acesso a direitos sociais, econômicos, civis e políticos. O direito à saúde amarra os sujeitos em uma complexa rede de cuidados e preocupações consigo mesmos que os conduz a aderir às práticas de saúde. Promover a vida envolve ações integrais do Estado e, por outro lado, a singularidade e autonomia dos sujeitos. As lutas para a formação de outro conceito de saúde acabam se acoplando com mais intensidade à formação biopolítica do fazer viver. $\mathrm{O}$ conceito de saúde, em um sentido ampliado, que engloba desde o corpo até a cultura e a sociedade, permite uma forma muito mais eficaz e complexa de governar a população, deixando o governo de intervir apenas nos processos biológicos para incidir também sobre o subjetivo, o social, o afetivo, o econômico. As práticas de saúde, como investimento nas condições de vida da população, geraram um movimento exacerbado de busca por qualidade de vida como um efeito desmedido da compreensão de que saúde envolve todos os fatores condicionantes da vida.

A exaltação da qualidade de vida extrapolaria o campo das legislações e teorizações do novo entendimento de saúde, gerando uma busca de longevidade e de perfeição da saúde físico-mental, bem como a negação do envelhecimento, da imperfeição física, do adoecimento e da morte. O mercado de consumo de bens de saúde teria incorporado esse investimento na saúde, disponibilizando à população diferentes meios capazes de retardar o envelhecimento e de corrigir imperfeições físicas, como a lipoaspiração das gorduras localizadas, o botox para a correção do envelhecimento, etc. A saúde, diante disso, não faz mais uso de práticas disciplinares e coercitivas, mas utiliza e envolve a população em um jogo duplo de tutela e de culpabilização, em que o sujeito deve creditar a si o sucesso de seus esforços para atingir a saúde perfeita e, caso venha a fracassar, deve se sentir culpado (Costa, 2001). A busca por qualidade de vida atualiza a proposta de liberdade presente nos ideais liberais, que promoveu um investimento na vida com mecanismos cada vez menos coercitivos e disciplinares, buscando formar sujeitos autônomos e aptos para o consumo.

Fortalecer a autonomia dos sujeitos e dos grupos sociais é um dos principais eixos de entendimento da noção contemporânea de saúde. A promoção de saúde requer o fortalecimento da capacidade individual e coletiva para lidar com a multiplicidade dos condicionantes da saúde. Promoção de saúde está além de uma aplicação técnica e normativa, aceitandose que não basta conhecer o funcionamento das doenças e encontrar mecanismos para seu controle: diz respeito ao fortalecimento da saúde por meio da construção de capacidade de escolha, bem como à utilização do conhecimento com o discernimento necessário para atentar para as diferenças e singularidades dos acontecimentos (Czeresnia, 2003). Essa liberdade oferecida pelo liberalismo maneja as populações de acordo com parâmetros de exclusão e eugenia, que são a forma pela qual o racismo de Estado atua, através do aperfeiçoamento e manutenção da vida. O racismo de Estado está estritamente amarrado às noções evolutivas, pois nesse enfoque os parâmetros de normalidade, de saúde e de doença são categorizados, são padronizados; dessa maneira, os que estão dentro do quadro esperado podem ser 
aprimorados, e aqueles que se desviam de tal quadro podem ser recuperados.

\section{A NOÇÃO DESENVOLVIMENTISTA DA PSICOLOGIA NAS PRÁTICAS DE SAÚDE}

$\mathrm{O}$ ingresso da vida biológica nas preocupações políticas colocou o todo da vida como centro das preocupações da produção dos saberes na Modernidade. Essa produção de conhecimento sobre a vida, demarcada, sobretudo, pelas Ciências Naturais no século XIX, pretendia "desvendar" as leis naturais que regeriam, especialmente, o corpo, a mente e a sociedade. Tal como na prática da biologia evolucionista, emergem práticas psicológicas destinadas ao controle dos sujeitos por meio do biopoder, ou pela valorização da busca de um suposto indivíduo autônomo, remetendo-o a uma ordem do natural. É nesses termos que discutimos a implicação das práticas psicológicas na saúde como ferramentas conceituais e de intervenção no investimento da vida na perspectiva de que a população se torne bem adaptada, sadia e integrada à ordem social.

As classificações produzidas pelas práticas psicológicas organizaram-se a partir da produção de seu saber sobre um sujeito dotado de um "mundo interno", de um "mundo de representações" que forja a figura de um sujeito privado. Este difere do sujeito privado da economia política, pois não se busca localizar essa experiência do privado, em um primeiro momento, no âmbito da economia doméstica, no âmbito do lar, mas localizá-la em um espaço interior, um espaço dentro do sujeito que não é específico da atividade cerebral, do organismo do ser vivo, mas é específico da condição humana, de sua relação com o passado e com o futuro. Isto diz respeito ao exame do humano naquilo que o diferencia das noções de natureza: a experiência de interioridade. Para Foucault (2002), o evolucionismo evidencia que o fato psicológico tem sentido apenas com relação a um futuro e a um passado e que seu conteúdo assenta-se em estruturas produzidas por esse passado que o carrega de uma história, mas ao mesmo tempo o envolve num horizonte aberto ao eventual.

As influências da história sobre o indivíduo, nesse viés evolutivo, são demarcadas pelos fenômenos de adoecimento que empurram a Psicologia para a condição de pertencente às Ciências Humanas, e não às Naturais. Tais fenômenos serão considerados na sua articulação com um plano de representações e significações mentais que formulam, de um lado, a estrutura do sujeito psicológico, figuras neuróticas, psicóticas, perversas, e de outro, a relação dessa estrutura com aquilo que é exterior à interioridade do sujeito - a sociedade, as instituições, a família, etc. Essa problemática da interioridade para o campo psicológico irá intensificar as formas de governo das vidas. Na medida em que a interioridade cria caminhos pelas relações que estabelece com a história de vida do indivíduo que a constitui - de modo a tornar a psicopatologia uma forma de objetivação das formas de viver -, abre-se um espaço de investimento governamental sobre a interioridade e, consequentemente, sobre as relações do sujeito (Guareschi, 2007).

As práticas psicológicas e outros campos de conhecimento, ao construírem modelos prévios, condicionam os indivíduos a buscarem alcançar esses modelos, e isso gera um esquema de tutela sobre a vida dos indivíduos. Esta tutela passa a ser um dos campos das práticas psicológicas diante do sujeito privado, que é responsabilizado pelos seus atos e escolhas, portanto é levado a agir de determinados modos, e não obrigado a fazê-lo. Trata-se de uma pretensa liberdade, pois o sujeito é livre para fazer suas escolhas, porém os modelos propostos nesse esquema de liberdade já estão previamente definidos. Apesar disso, vale destacar que, quando dizemos que as práticas psicológicas criam esses modelos, estamos falando da importância desses domínios de conhecimento para a produção de todo um arranjo que envolve o sujeito, o Estado, as instituições e os saberes na produção dos modos de subjetivação, ou seja, nos modos em que o sujeito aparece como objeto de uma determinada relação de conhecimento e de poder. A Psicologia, nesse sentido, cria e legitima os regimes de verdades que delimitam o que é ser criança, adolescente, adulto, idoso e os demais desdobramentos dessas categorias: jovem delinquente, criança hiperativa, etc.

Esse esquema de tutela torna-se possível quando se alia aos ideais modernos da saúde como uma questão de polícia (Foucault, 2005) - polícia no sentido da vigilância panóptica abordada por Foucault (1995), na qual todos passam a ser observados sem haver um observador externo. É uma autovigilância; o sujeito é o próprio regulador de seu dito mundo interno e de suas relações com o exterior. A Psicologia apresenta-se como uma possibilidade de salvaguardar individualidades - o neurótico, a histérica, o deprimido, o esquizofrênico -, e é a possibilidade de objetivação do indivíduo, de falar, tratar e desvendar os diversos tipos de indivíduos do sujeito privado, o que dá à Psicologia um status, um regime de verdade.

Queremos dizer que é por meio do governo da economia psíquica, das práticas de exame e confissão, 
de um tribunal de condutas e condicionamentos, que a Psicologia começa a tornar-se uma estratégia de controle das populações. A economia psíquica é a forma pela qual as práticas psicológicas inscrevem o "eu" individualizado e interiorizado como a base de uma narrativa histórica. Isso implica voltar-se para os efeitos dessa economia no que tange à problemática da conduta do em relação a si mesmo ou aos outros. A inteligibilidade e a visibilidade que as práticas psicológicas produzem possibilitam tanto a necessidade de administração da economia psíquica quanto a forma personalizada como esta será administrada. As práticas psicológicas permitem criar uma fronteira entre o público e o privado, objetivando o primeiro como população/pobreza/Estado organizados em comunidades periféricas, e o segundo, como o "eu interior" envelopado pela pele. Essas práticas começam a entrar no cotidiano das comunidades mediante tecnologias de bem-estar social. O foco não é propriamente o interior do sujeito, mas sim, a forma de manifestação desse interior em termos de comportamento, de conduta, de hábitos diários, um território no qual o indivíduo se torna inteligível e praticável segundo um modelo de equilíbrio social

A vivência da interioridade e da exterioridade do indivíduo privado é organizada mediante uma predefinição de uma normalidade definida a partir da invenção das fases do desenvolvimento humano: infância, adolescência, idade adulta e velhice. À Psicologia, assim com a outras tantas áreas do conhecimento, é concedida a autoridade de falar sobre essas fases e definir os parâmetros de normalidade e anormalidade que estabelecem regimes de verdade e permitem o manejo das populações infantis, adolescentes, adultas e idosas, moldando-as e conduzindo-as nas direções desejadas. A criação das noções dessas fases do desenvolvimento humano e as implicações das práticas psi para essa invenção remete-nos ao que Foucault (1999) chamou de "corpo político"; ou seja, considerar a produção de conhecimentos sobre estas categorias é pensar em um

conjunto de elementos materiais e de técnicas que servem de armas, de reforço, de vias de comunicação e de pontos de apoio para as relações de poder e de saber que investem nos corpos humanos e os submetem a uma condição de objetos de saber (Foucault, 1999, p.27).

Como diz Rose, "a Psicologia, como um corpo de discursos e práticas profissionais, como uma gama de técnicas e sistemas de julgamento e como um componente de ética, tem uma importância particular em relação aos agenciamentos contemporâneos de subjetivação" (2001b, p. 146). Assim, a Psicologia exerce também o papel de definir as características e os critérios balizadores para a classificação das populações.

As divisões das fases do desenvolvimento do sujeito tiveram uma rígida cronologização do curso da vida individual, com vistas à obtenção de um critério objetivista e naturalista para a determinação da idade de cada indivíduo, o que ocasionou uma profusão de saberes científicos e jurídicos sobre estágios da vida (Groppo, 2000). A noção de idade, no entanto, na perspectiva discursiva que assumimos, pode ser tomada como uma marca que nos posiciona no mundo - como marcadores identitários que se inscrevem como símbolos culturais que diferenciam, agrupam, classificam e ordenam as pessoas conforme marcas inscritas na cultura, sobretudo, na cultura do corpo, "cujos significados nem são estáveis nem têm a mesma importância ou penetração relativa, combinamse e recombinam-se permanentemente entre si" (Veiga-Neto, 2000, p. 215). Com essa noção relativa às idades, questionamos a visão instituída por um pensamento psicológico desenvolvimentista que estabelece as características inerentes a cada uma das etapas da vida. Da mesma forma, a constituição e objetivação da vida cronologizada em etapas a serem percorridas é fruto dessa vertente psi de cunho evolutivo. Se, por um lado, é na Modernidade que se produzem as concepções de infância, juventude, idade adulta e velhice como as conhecemos hoje, por outro, a própria constituição da sociedade moderna, com instituições como a saúde, a escola, o Estado, o direito e o trabalho industrial, assentou-se "no reconhecimento das faixas etárias e na institucionalização do curso da vida", mostrando-nos um mútuo engendramento de mudanças e institucionalizações na rede social no período moderno, o que se configurou também como um solo fértil para a objetivação das idades (Groppo, 2000).

Nesse processo, a Psicologia institui bases fundamentais para a compreensão da natureza humana e do desenrolar evolutivo das idades - da infância à idade adulta - gerando saberes e práticas em torno desse homem/indivíduo. Cada indivíduo, segundo essa lógica, passaria a ter certeza de que, em determinado momento, o sinal da natureza iria despertar nele transformações biopsicossociais prediagnosticadas pelas ciências médicas e psicológicas. É nesse sentido, ainda, que as disciplinas psi, como diz Rose, "estabeleceram uma variedade de 'racionalidades práticas', envolvendo-se na multiplicação de novas 
tecnologias e em sua proliferação ao longo de toda a textura da vida cotidiana: normas e dispositivos de acordo com os quais as capacidades e a conduta dos humanos têm se tornado inteligíveis e julgáveis" (1999, p.147). É ancorada, principalmente, nessa lógica desenvolvimentista - que preconiza um progresso contínuo da humanidade no qual o indivíduo, a partir de seus "estágios iniciais", vai se desenvolvendo em etapas predefinidas cada vez mais rumo à maturidade do adulto - que a Psicologia vem prescrevendo e legitimando concepções acerca da infância e juventude, ordenando-as e objetivando-as em uma ordem social entre as fases de transição da infância para a maturidade, o período adulto. Assim, tomar essa lógica desenvolvimentista como uma racionalidade prática significa indagar-se sobre as práticas culturais e históricas que produzem e legitimam a experiência do crescimento a partir de uma evolução inerente à vida das pessoas. Esse processo não se dá de forma determinista, mas cria as diferentes possibilidades de produção de subjetividade no contemporâneo.

Sabemos que as práticas de governo psi, fundadas em um determinado saber anterior à Reforma Sanitária, forjam o privado e justificam-no como uma forma de proteção do conjunto da população, ou seja, como lócus de doenças que devem ser eliminadas; porém a Reforma Sanitária supera essa relação centrada na doença e passa a trabalhar com a noção de qualidade de vida. Não obstante, nesta transição conceitual, a Psicologia ainda pouco evidencia uma mudança em suas práticas do seu entendimento de saúde, já que a maneira como a Psicologia subsidia os jogos de biopoder se dá pela intensificação da privatividade do indivíduo por meio de práticas e procedimentos que não apenas o tornam responsável pelos processos de adoecimento, mas o mantêm responsabilizável.

\section{BIOTECNOLOGIAS E EVOLUÇÃO ARTIFICIAL}

No final do século XX o racismo de Estado de cunho evolucionista começa a delinear-se de outros modos. Os critérios daqueles que podem ou não ser mortos ou desinvestidos passam a sofrer alterações. Com o desenvolvimento das biotecnologias (medicina nuclear, engenharia genética...), o evolucionismo, antes ligado aos processos naturais das espécies, vai ser atravessado por uma série de intervenções técnicocientíficas que provocarão alterações artificiais no processo evolutivo. Somos contemporâneos do engendramento de um evolucionismo artificial (Sibilia, 2002). Essas alterações têm efeitos nos modos como o racismo de Estado é utilizado como mecanismo de fazer viver mais e melhor, uma estratégia de biopoder.

No estágio contemporâneo desse processo a palavra "natureza" perdeu seu sentido etimológico, que vem do latim "natura", termo relacionado a nasci, que pode ser traduzido por "ser nato". Com tamanhas interferências dos seres humanos sobre a Terra, podemos ainda ousar falar da natureza das coisas, dos seres vivos ou de nós mesmos? Parece que todos nós, seres humanos e não humanos, estamos perdendo nossa natureza. Para que fique mais exato nosso posicionamento, não seria uma questão de uma natureza que se desfaz. É importante salientar que não queremos, como alguns pensadores, alertar que o natural está sendo "contaminado" ou que nossa evolução ou destino estão perdidos. Tampouco queremos colocar-nos no lugar daqueles que, ao falarem de um futuro póshumano ou trans-humanista, consideram que as intervenções nos seres humanos são violações em nossa natureza humana. Como diria Foucault (2006), a noção de natureza humana não seria um conceito científico, mas um indicador epistemológico que classifica e diferencia, que coloca em oposição ou em relação os discursos da biologia, teologia, história, etc. Assim, preferimos assumir uma postura próxima à de Nikolas Rose (2007), que inclui como elemento para a análise de uma forma de vida emergente esses tipos de julgamentos, avaliações, temores, esperanças, especulações e meditações sobre nosso presente. No que se entendia por categoria invariante, aponta-se para seu caráter inventivo, ou seja, uma ideia que varia nas diversas formações sociais, de acordo com os tipos de saberes e poderes nelas gerados. A formação discursiva de natureza vai ganhando outros contornos no pensamento ocidental, seja pelas biotecnologias seja pelas incríveis interações entre os seres vivos e as máquinas, seja pela gama de práticas, técnicas e racionalidades. Finalmente, a análise e a discussão dos problemas deste artigo a partir da perspectiva de Michel Foucault estão sendo, até aqui, permeadas pela pergunta sobre as contingências que nos fazem ser o que somos através do desassujeitamento dos saberes históricos.

Pensemos em algumas práticas contemporâneas como, por exemplo, a das mutações genéticas criadas por manipulação em laboratório, e mesmo aquelas geradas por resíduos industriais, ou em toda a maquinaria utilizada em nosso cotidiano, teoricamente necessária para nossa sobrevivência. 
Estamos em uma era da integração entre a genética e a reprodução tecnológica, no mundo da engenharia humana e animal, com qualidades e capacidades de fabricação de acordo com a demanda. Este é o momento da nova geração de psicofármacos endereçados ao rearranjo de nosso ânimo, emoções, desejos e inteligência; é uma época de se sonhar com o prolongamento indefinido da vida, na tentativa de superar a morte. Ao que tudo indica, estamos entrando no século biotecnológico (Rose, 2007).

$\mathrm{Na}$ atualidade o artificial impregnou nosso cotidiano e muitas vezes já não fazemos a diferença entre o natural e o artificial. A dita civilização, em seu processo de se tornar máquina, ultrapassa o nível mecânico, atingindo um nível cibernético, para assim só pensarmos em bits (Deleuze, 1992). Há uma junção incrivelmente espantosa entre a engenharia genética e o instrumental informático, fazendo com que a ciência já possa manipular em seus laboratórios o código da vida. Dessa forma, voltamos a perguntar sobre o que tomaríamos por natureza e incrementamos a questão indagando se é ainda possível falar em evolução natural.

Após perdermos nosso lugar privilegiado no centro do universo, tendo como marca emblemática nessa quebra de paradigma a teoria heliocêntrica do sistema solar de Copérnico, nós, seres humanos, entramos no mesmo nível ontológico dos animais e das plantas, quando Darwin cria a teoria que coloca os humanos como mais uma espécie gerada pela evolução, mais um produto da natureza. A teoria darwiniana da evolução perdura até hoje como explicação e crença principal de nossa origem, mesmo que atualmente ela sofra críticas e já não mais se sustente pelas condições como o mundo está se organizando. Por um lado, não podemos mais falar em evolução natural das espécies quando, com a criação industrial e tecnológica, os números de espécies exterminadas por dia podem chegar até uma centena, seja pela chuva ácida ou pela poluição do ar, seja pelo desmatamento ou pelas queimadas, milhares de hectares de terra no planeta vão perdendo sua utilidade. Da mesma forma, a água e todas as formas de vida que nela habitam, ou sofrem mutações químicas inesperadas ou morrem. Por outro lado, é inviável falar em evolução natural das espécies, justamente pelos seus processos de multiplicação, de diversificação e de especialização (Kesselring, 2000) que ocorrem ao acaso por todas as alterações ambientais ou que se sucedem por intermédio do ser humano e de suas ferramentas e máquinas. Lembremo-nos aqui da clonagem, dos transplantes de órgãos, dos organismos geneticamente modificados, dos xenotransplantes (transplantes de órgãos animais para seres humanos), da medicina personalizada na reparação de cada genótipo individual codificado em microchips, da fabricação e regeneração de órgãos in vitro, dos diversos tipos de próteses, das cirurgias plásticas, dos alimentos modificados, e assim por diante.

Diante dos modos como a noção de evolução vai tomando outros contornos, desde a perspectiva darwiniana de evolução natural até os dias de hoje, já é possível pensar no conceito de evolução artificial. Artificial porque a noção de evolução não transcorre mais para os seres humanos e para outros seres da mesma forma como em tempos atrás. A lógica da lei da natureza, do mais forte vencendo o mais fraco, não parece perdurar - apesar de sabermos que esta perspectiva darwiniana, em um nível sociológico, encaixa-se perfeitamente nos parâmetros capitalistas de poder e lucro. Não se sustenta também a ideia contemporânea de natureza, que não se refere ao mais forte, mas ao mais bem-adaptado, que tem flexibilidade para cooperar e concorrer ao mesmo tempo - ainda quando temos consciência de que este tipo de concepção se aproxima grandiosamente do projeto neoliberal. Estamos em um tempo no qual se planeja a vida em laboratório, pois o Projeto Genoma Humano já anunciou o sequenciamento total do genoma e, antes mesmo disso, a Declaração Universal sobre genoma humano e os direitos humanos já trazia como princípio o genoma humano subentendido como unidade fundamental de todos os membros da família; ou seja, temos um mapa da estrutura que subjaz ao desenvolvimento do corpo (Hüning, 2008). "A diversidade dos corpos humanos se acha então inscrita em um livro único, cujo produto são suas histórias singulares" (Keck \& Rabinow, 2008, p. 84). Com esta descoberta, um casal pode verificar se seu futuro filho terá alguma anomalia, enquanto outro casal pode escolher as características físicas de seu bebê. Não precisamos pensar apenas em casais, pois sabemos da existência da reprodução in vitro. Para além dos seres humanos, temos a transgenia tanto de animais quanto de vegetais, que têm a sua estrutura genética modificada ao serem inseridos genes vindos de outros. Assim teríamos ainda muitos exemplos de como a vida pode ser planejada e ainda deixamos de lado comentários sobre a morte, que já não parece ser um fim tão certo para nós - somente como exemplo extremo, vale 
lembrar da prática, cada vez mais em alta, da criogenia, que se refere à conservação em baixa temperatura de material biológico; no caso, estamos falando do congelamento do corpo (Iwasso, 2002) ou do cérebro (Pérez, 2006) pós-morte. Enfim, as pouco confiáveis mutações aleatórias e seus lentos processos de seleção da evolução natural já não nos fazem mais tanto sentido, abrindo-se caminho para o que pode ser chamado de evolução pós-biológica ou pós-evolução.

Os três eixos, saúde, psicologia, evolucionismo este agora artificial, tomam outros contornos, como se pode ver com o investimento técnico-científico nas características biológicas que pautaram modelos de classificação dos seres superiores e inferiores de acordo com critérios biotecnológicos. A exclusão e a eugenia propagam-se em um nível que Nikolas Rose (2007) denomina de biopolítica molecular. Podemos dizer que a clínica médica do século XIX manteve relação com um nível molar de nosso corpo, em uma escala dos tecidos, órgãos, hormônios e assim por diante, e os efeitos disso são nossas tentativas de aperfeiçoar nosso corpo molar através de dietas, exercícios, tatuagens e cirurgias - o esforço por uma qualidade de vida. Atualmente, um estilo molecular de pensamento sobre nossas vidas tomou forma com a criação em laboratório de novas formas de vida moleculares, fabricando uma nova forma de entender a vida em si. A indústria farmacêutica, as técnicas de visualização médica e as tecnologias de decomposição, anatomização, manipulação, amplificação e reprodução da vida em nível molecular conferem uma nova mobilidade aos elementos da vida, interferindo nos circuitos orgânicos, interpessoal, geográfico e financeiro. A biopolítica molecular refere-se a todos os elementos moleculares da vida que podem ser mobilizados, controlados e combinados em processo que não existia anteriormente (Rose, 2007). Tais modificações acabam por reformular os diferentes campos do conhecimento e, em decorrência, os processos de subjetivação. No campo da saúde, parece mais evidente o modo como essas reformulações vêm acontecendo; no entanto, no campo da Psicologia isso parece ainda uma questão a ser investigada. Cabe indagarmos o que pensar de uma psicologia biotecnológica.

\section{REFERÊNCIAS}

Brasil. (1986). Relatório da VIII Conferência Nacional de Saúde. Recuperado em 10 de dezembro 2009, de http://conselho.saude.gov.br/biblioteca/Relatorios/relatorio_8.pdf.
Costa, J. F. (2001). A subjetividade exterior. Palestra apresentada sob o título de A Externalização da Subjetividade. Texto inédito. Recuperado em 10 de agosto de 2009, de http://jfreirecosta.sites.uol.com.br/artigos/artigos_html/subjetivida de.html.

Czeresnia, D. (2003). O conceito de saúde e a diferença entre prevenção e promoção. In D., Czeresnia, C. M., Freitas (Orgs.), Promoção da Saúde: conceitos, reflexões, tendências. Rio de Janeiro: Fiocruz.

Deleuze, G. (1992). Conversações, 1972-1990. (Pál Perbart, T., Trad.). São Paulo: Ed. 34.

Foucault, M. (1995). Microfisica do Poder. Rio de Janeiro: Graal.

Foucault, M. (1999). Vigiar e Punir: história da violência nas prisões. (21a ed.). Petrópolis: Vozes.

Foucault, M. (2002). A Psicologia de 1850 a 1950. In M., Foucault. Ditos e escritos I. Rio de Janeiro: Forense Universitária.

Foucault, M. (2003). História da sexualidade I: a vontade de saber (15a ed.). São Paulo: Edições Graal.

Foucault, M. (2004) A arqueologia do saber. (7a ed.). Rio de Janeiro: Forense Universitária.

Foucault, M. (2005). Em defesa da sociedade: curso no Collège de France (1975-1976). São Paulo: Martins Fontes.

Foucault, M. (2008). Nacimiento de la biopolítica. Curso en el Collège de France (1978- 1979). Buenos Aires: Fondo de Cultura Económica.

Groppo, L. A. (2000). Juventude: Ensaios sobre Sociologia e história das juventudes modernas. Rio de Janeiro: Difel.

Guareschi, N. M. de F. (2007). Infância, adolescência e a família: práticas Psi, sociedade contemporânea e produção de subjetividade. In A., Jacó-Villela, L., Sato (Orgs.), Diálogos em Psicologia Social. Porto Alegre: Evangraf. pp. 229-239.

Hüning, S. M. (2008). O sujeito biotecnológico na viagem pelo reino das batatas transgênicas, porquinhos fosforescentes e almas codificadas. Tese de Doutorado, Pontifícia Universidade Católica do Rio Grande do Sul, Porto Alegre.

Iwasso, S. Folha Online "Cresce interesse por congelamento pósmorte" Recuperado em 19 de dezembro, 2002, de http://www1.folha.uol.com.br/folha/equilibrio/noticias/ult263u20 01.shtml

Keck, F., \& Rabinow, P. (2008). Invenção e representação do corpo genético. In A, Corbin, J., Courtine, G., Vigarello (Org.), História do corpo: as mutações do olhar: o século XX. Rio de Janeiro: Vozes. pp. 83-108.

Kesselring, T. (2000). O Conceito de Natureza na História do Pensamento Ocidental. Episteme, no. 11, p. 153-172.

Lei 8080, de 19 de setembro de 1990 (1990). Dispõe sobre as condições para a promoção, proteção e recuperação da saúde, a organização e o funcionamento dos serviços correspondentes e dá outras providências. Recuperado em 12 de fevereiro, 2010, de http://portal.saude.gov.br/legislacao.

Pérez, A. Folha Online. Rússia cria banco de cérebros e corpos congelados. Recuperado em 19 de maio 2006, de http://www1.folha.uol.com.br/folha/ciencia/ult306u14644.shtml

Rose, N. (2001a) Como se deve fazer a história do eu? Educação \& Realidade, 26(1), 33-57.

Rose, N. (2001b). Inventando nossos eus. In T. T., Silva. Nunca fomos humanos: nos rastros do sujeito. Belo Horizonte: Autêntica. 
Rose, N. (2007). The Politics of Life Itself: Biomedicine, Power and Subjectivity in the Twenty-First Century. United Kingdom: Princeton University Press.

Sibilia, P. (2002). O homem pós-orgânico. Rio de Janeiro: Relume Dumará.

Silva, R. N. (2004). Notas para uma genealogia da Psicologia Social. Psicologia \& Sociedade, 16 (2), 12-19.

Veiga-Neto, A. (2000). As identidades do corpo (material)idades, (divers)idades, (corporal)idades, (ident)idades. In J. C., Azevedo, P., Gentili, A., Krug, \& C., Simon. (Orgs.), Utopia e democracia na educação cidadã. Porto Alegre: Ed. Universidade UFRGS/SMED.

Veiga-Neto, A. (2005). Foucault e a Educação. (2a ed.). Belo Horizonte: Autêntica.
Endereço para correspondência:
Neuza Maria de Fátima Guareschi. Rua General Souza Doca, 270, apto 301, Bairro Petrópolis, CEP 90630-050, Porto Alegre-RS, Brasil.E-mail: nmguares@ gmail.com. 